\title{
The Mental Health and Physical Ergonomic Impact on Executive Performance
}

\author{
Wan Mohd Rafiq Bin Wan Mohd Raimi ${ }^{1}$, Siti Nur Fadzilah Muhsain ${ }^{2}$, Samsudin Wahab ${ }^{3}$, Adi \\ Izhar Che Ani ${ }^{4}$, Nor Aziyah Bakhari ${ }^{5}$, Ahmad Rashidy Razali ${ }^{6}$ \\ \{wanmohd.rafiq@gmail.com ${ }^{1}$, sitinurfadzilah077@uitm.edu.my², samsudinw@uitm.edu.my ${ }^{3}$, \\ adiizhar@uitm.edu.my ${ }^{4}$, noraziyah140@uitm.edu.my ${ }^{5}$, ahmad073@uitm.edu.my ${ }^{6}$ \} \\ Universiti Teknologi MARA, Cawangan Pulau Pinang, Malaysia ${ }^{1}$, Universiti Teknologi MARA, \\ Cawangan Pulau Pinang, Malaysia ${ }^{2}$, Universiti Teknologi MARA, Cawangan Pulau Pinang, Malaysia ${ }^{3}$, \\ Universiti Teknologi MARA, Cawangan Pulau Pinang, Malaysia ${ }^{4}$, Universiti Teknologi MARA, \\ Cawangan Pulau Pinang, Malaysia ${ }^{5}$, Universiti Teknologi MARA, Cawangan Pulau Pinang, Malaysia ${ }^{6}$
}

\begin{abstract}
Job performance for an executive is one of the main factors that contributes to the profit return of any organization. It is suppose organization's performance should be the primary basis for evaluating its executives. Mental health and ergonomic are considered as prominent factors contributing to executive's performance today. However, little is known regarding the impact of mental health and ergonomic towards an employee or executive group's performance in Malaysia, as well as the issues have become an emerging and growing statically day by day. Therefore, we tend to conduct further literature analysis to close the research gap by collecting and present an empirical data on the impact of mental health and physical ergonomic towards an executive performance in the context of private sector in Northern Malaysia.
\end{abstract}

Keywords: Mental Health, Physical Ergonomic, Performance, Absenteeism, Presentism.

\section{Introduction}

Job performance for an executive is a key factor that influence the profitability of any organizations. Organization's performance should be the major basis when evaluating its executives. Mental health, specifically on work related, is becoming an emerging issue towards executive in the organization. Studies have indicated that mental health is related to task performance [1]. According to 2015 National Health Morbidity Survey [2], 29\% of Malaysian population suffered from depression and anxiety disorder. It has been anticipated then that mental illness will be the second major issue affecting Malaysia after heart disease by 2020 . On top of that, there is ongoing global issues related to work performance to the ergonomics factor (office well - being). Several studies from past researchers had addressed the performance related issue with respect to the office wellbeing. Poor ergonomic conditions contribute to work injuries and this will contributes to overall expenses of organizations [3]. Accordingly, this paper provides reviews of available literature on the subject of mental health and ergonomic, and its relationship with executive job performance. 


\section{Literature Review}

\section{Determinant of Job Performance}

2.1 Mental Health

Mental health disorder is a global health issue that contribute to considerable proportion of health problems in most countries. The Global Burden of Disease Study (GBOD 1990) has projected that mental disorders to be a major world's disease burden. According to Malaysian Mental Healthcare Technical Report, 2016, globally, psychiatric disorders accounted for 10\% of Disability Adjusted Life Years (DALYs) and 28.5\% of global Years Lost due to Disability (YDLs) .Thus, mental health is an important element of performance indices for an employee and should be appropriately managed as it can negatively affects life as well as job functions. The National Institute of Mental Health (NIMH) 2015 reported that $17.9 \%$ Americans developed symptoms such as depression, anxiety, obsessive-compulsive tendencies, obsessive thought and feelings of impulsiveness. These has cause lost workdays and turnover, as well as absenteeism. Inappropriate management of mental illness can limit or interfere with daily activities that eventually lead to total disability, and financially burden a country [1].

Poor work conditions contributes to stress among employees and productivity that impacted on the economy. In view of this, World Health Organization (WHO) has promoted a healthy workplace through preventing issues associated with mental and health problem such as stigma, discrimination, and integration. Depression resulted in $13.7 \%$ disabilities, and $30 \%$ occupational disabilities in German are due to mental health problem. The increasing rate of absenteeism are the result of mental health and disabilities. Mental health problems in the workplace affect not only the employee but also productivity and competitiveness of business and thus the economy and society altogether. Poor employee's mental health affects the job performance, illnesses, absenteeism, which negatively impact productivity and overall income. Workplace stress and mental health disorder can lead to social exclusion from workforce and early retirement that account for a substantial share of long-term benefits. World health Organization estimated that in United Kingdom, $£ 26$ billion each year is spent by employers for employees with mental health problems. Annually, this led to business costs of $£ 8.4$ due to sickness absence, $£ 15.1$ billion from decreased productivity and $£ 2.4$ billion to replace employees who resign due to mental health. There is a variation of mental health related productivity across occupations and thus estimating their impact and proper intervention in workplace are crucial [4].

It is estimated that poor mental health in men and women similarly reduce productivity at workplace by 6.17 and 6.19 times higher respectively, than those with good mental health. [5]. Emotional stability, which is related to mental health and conscientiousness, is a constant predictor of overall work performance [6]. Poor decision-making ability, lack of effort and commitment, worsen the stress and internal conflict. Job burnout, depression and stress related conditions such as hypertension, sleeping disorders and susceptibility to infections can increase overall sickness, absenteeism, occupational disability that lead to early retirement. Employees might change their emotion, perceptions of work stressors and physical health, absenteeism and presenting, decreased work performance, and interpersonal challenges. It is critical for organizations to understand these consequences as mental health and require organization's support in prevention and treatment.

\subsection{Physical Ergonomic}

Ergonomics is the design of the workplace, equipment, machine, tool, product, environment and system, taking into consideration the human's physical, physiological 
capabilities and optimizing the effectiveness and productivity of work system while assuring the safety, health and wellbeing of the workers. Ergonomics, also known as human factors, can be defined as a study of work and the interaction between people and their environmental work systems. Providing appropriate and necessary working environment to employees enhance well-being that enable them to complete tasks given. Ergonomics represents human endeavour. As a result, various concepts of Ergonomics developed over the years. It is related to the office setting such as workstations, computers, furniture, lighting, noise level and room temperature. All these factors must be appropriately considered to enhance employee's wellbeing, safety and job productivity. BNet Business Dictionary (2008) conclude office as the place where the business conducted, clerical work and professional activities. It includes site offices as well as permanent multi-storey corporate organizations and a critically supports business activities and aid employees to complete their job. As a summary, office ergonomics links the office and people. Hence, human-cantered design considers knowledge of the people particularly of their capabilities, and their preferences. The Office Ergonomics Handbook (2008) identifies the under-listed as the key ergonomic elements in the office:

Efficient and high-performing employees are assets and one of critical factor to determine organization competitiveness, productivity and attainment of corporate goals. Tasks accomplishment and performing at a high level can provide a sense of satisfaction, pride and improve self-esteem. The action (i.e. behavioural) and an outcome aspects defines employee performance. The behavioural aspect refers to what an individual does in the work situation. The outcome aspect refers to the consequence or result of the individual's behaviour. Employee performance can be defined as the extent to which an organizational member contributes to achieving the goals of the organization.

Ergonomic factors contribute to employee's performance. The design and layout of workplace that consider ergonomic, comfortable and conducive working environment can helps employees to function efficiently that eventually optimize the value of the human capital of any organizations.

However, [8] did an ergonomic study among 154 academic staff in Umm Al - Quran University had found the performance level of academic staff is high regarding the workplace ergonomic. This might has some dispute from previous study that carried out by numbers of other fellow researchers. Since there is an inconsistency from previous study and literature, we have an interest to continue the study pertaining this matter in our own context. Hence, it is undoubtedly mental health and ergonomic are considered as prominent factors contributing to an executive performance. However, there is still little research regarding the impact of mental health and ergonomic towards an employee or executive groups performance available in Malaysia. Most literature and studies that investigate the impact of mental health on work performance only been conducted in Western countries [4]. Despite the financial impact of these hidden cost on organization's performance, these types of expenses are usually ignored [3]. Therefore, we tend to conduct further analysis to close the research gap by collecting and present an empirical data on the impact of mental health and ergonomic towards an executive performance in the context of private sector in Northern Malaysia.

\section{Methods}

This paper represents the literatures on mental health and ergonomic issues in achieving high office productivity in the organization. This basis article is on the earlier stage of 
proposal before conducting a real field research to prove the hypothesis. Therefore, this article is discussing the reviewed of available literature about contamination and supply chain variable as the determinants of food safely.

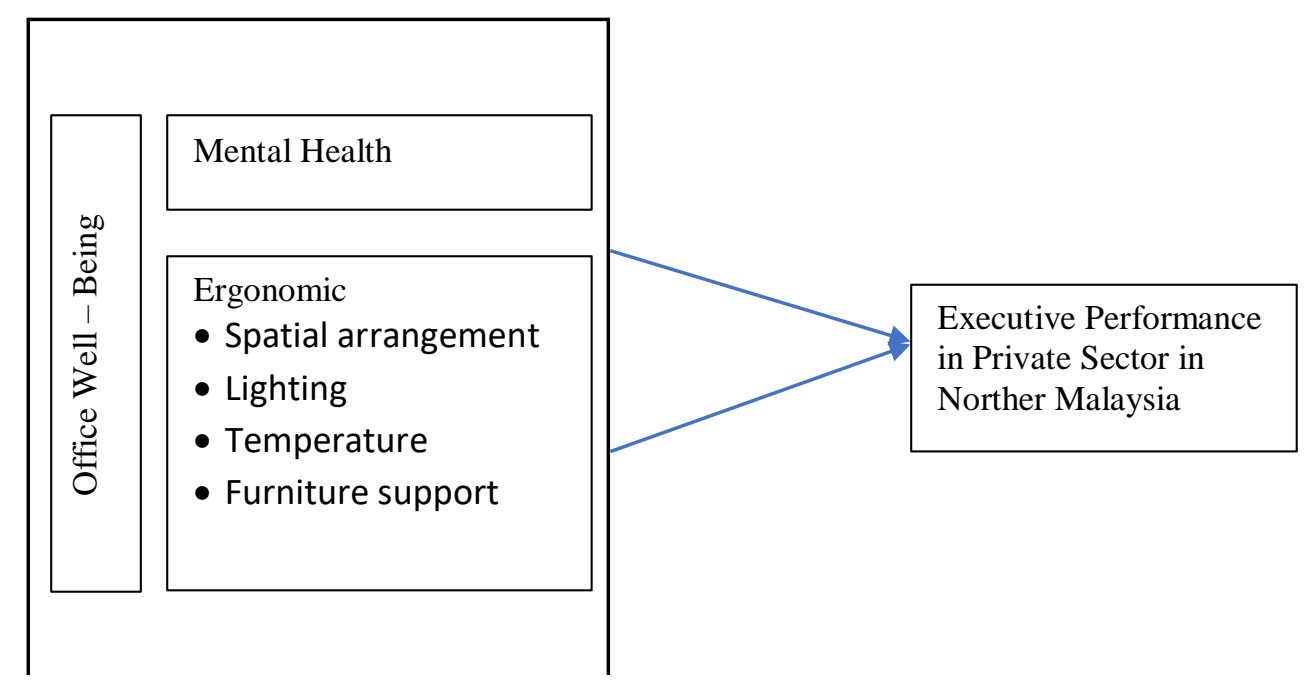

Figure 1. Propose Theoretical Framework

The dependent variable is the executive performance in private sector in Northern Malaysia, and the independent variables are mental health and physical ergonomics. In this research, the focus is the work-related productivity loss stemming from employee's mental health/illness as well as the physical ergonomic factor i.e., in work absence (absenteeism) and diminished on-the-job productivity (presentisms).

$\mathrm{H} 1$ - There is a significant impact between Mental Health and Executive Performance in Private Sector in Norther Malaysia

H2 - There is a significant impact between Ergonomics and Executive Performance in Private Sector in Norther Malaysia

\section{Result and Discussion}

The proposed conceptual framework directed the research to two important value of observations. First, loss of productivity which is associated with mental health/illness and physical ergonomics will depend on wider definition and range of the factors including:

Absenteeism might happen due to lack of creativity among the staff. Even in the earlier literature confirm that mental illness is not related to work performance but sometime its effect staff commitment in the workplace. The factors like lighting system, chair and table condition more closed to staff movement whereby directly affect their creativity at work. 
Comfortable workplace area will reduced mental illness due to free open plan office and systematic ergonomic.

\section{Conclusion}

The claims and arguments that mental illness as well as the physical ergonomics takes on worker productivity will results to a substantial economic lost in term of direct and indirect costs to the firms, employees, and might as well goes to the society and nation in more general view.

The potential for reducing these costs laid in large part on employers developing an employment policies and workplace cultures that support their mentally ill employees and have a clear policies regarding the healthcare in term of mental and work ergonomic environment, so that employees are not only have a good attendance record attending work, but also being productive and deliver while they are working.

Based on our research theoretical framework as in 3., it explains the relationship between mental health and physical ergonomics and their impact towards employee's performance. The framework, as per previous literature, assumes the resultant impacts of mental health and physical ergonomics directly towards the performance of an executive in private sectors in Northern Malaysia, and associated to the financial aspect.

\section{Acknowledgements}

Acknowledgements. Special appreciation to Dr. Nor Aminin binti Khalid, Dr. Samsudin bin Wahab, and Universiti Teknologi MARA, Cawangan Pulau Pinang for providing the budget for this research proposal.

\section{References}

[1] D. Auten and C. Fritz, "Mental health at work: How mindfulness aids in more ways than one," Organizational Dynamics. 2019, doi: 10.1016/j.orgdyn.2018.04.001.

[2] I. for P. Health, "National Health and Morbidity Survey 2011 (NHMS 2011)," Vol. II NonCommunicable Dis. Risk Factors Other Heal. Probl., 2015.

[3] M. Mansour, "Quantifying the intangible costs related to non-ergonomic work conditions and work injuries based on the stress level among employees," Saf. Sci., 2016, doi: 10.1016/j.ssci.2015.09.007.

[4] M. Tsuchiya et al., "Impact of mental disorders on work performance in a community sample of workers in Japan: The World Mental Health Japan Survey 2002-2005,” Psychiatry Res., 2012, doi: 10.1016/j.psychres.2011.10.014.

[5] M. Bubonya, D. A. Cobb-Clark, and M. Wooden, "Mental health and productivity at work: Does what you do matter?," Labour Econ., 2017, doi: 10.1016/j.labeco.2017.05.001.

[6] M. Lado and P. Alonso, "The Five-Factor model and job performance in low complexity jobs: A quantitative synthesis," Rev. Psicol. del Trab. y las Organ., 2017, doi: 10.1016/j.rpto.2017.07.004.

[7] Malaysian Healthcare Performance Unit, Malaysian Mental Healthcare Performance: Technical Report 2016. Putrajaya, Malaysia: Ministry of Health, Malaysia, 2016: 1-67

[8] H. G. Masterizki, A. Armanu, and D. W. Irawanto, "HOW ERGONOMIC FACTORS CONTRIBUTE TO EMPLOYEES'PERFORMANCE,” J. Apl. Manaj., vol. 17, no. 2, pp. 227 234, 2019. 